\title{
Review
}

\section{A Review of Building Construction Cost Research: Current Status, Gaps and Green Buildings}

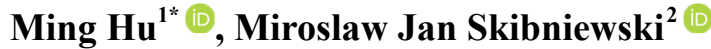 \\ ${ }^{1}$ Architecture Program, University of Maryland, Maryland, U.S. \\ ${ }^{2}$ Civil and Environmental Engineering, University of Maryland, Maryland, U.S. \\ E-mail:mhu2008@umd.edu \\ Received: 14 January 2021; Revised: 19 March 2021; Accepted: 6 April 2021
}

\begin{abstract}
An overall scoping review was conducted to examine research on building construction costs in the past decades. The aim is to provide a better understanding of conventional building construction cost estimation methods, gaps and potential improvement strategies that may mitigate the high risk of the cost overrun in conventional and sustainable building. This study first examined the components included in a building's construction cost and the commonly used calculation methods for cost estimation. Then, additional components included for sustainable buildings were identified and explained. The causal factors for construction cost overruns in sustainable building were discussed as well. The findings concluded the following: (a) there is no consistent cost definition used in the industry; (b) a variety of cost estimation methods create ambiguity and confusion; and (c) newer cost estimating methods and tools, such as parametric cost estimation, which integrate risk and uncertainties have not been broadly adopted by the building industry. The current practice used to determine a sustainable building's cost estimation is the same traditional method that has been used over several decades, which is based on the material and labor costs. Such a conventional approach does not consider other factors, including the complexity of the sustainable building system, an organization's environment, and the capability of teams, among others. To respond to such a knowledge gap, a comprehensive and consistent cost estimation framework was proposed to integrate risk and uncertainty consideration, which is particularly prevalent in sustainable building.
\end{abstract}

Keywords: sustainable building, construction cost, estimation

\section{Introduction}

The construction industry is an integral part of a country's economy, and the industry's growth is a conduit for a substantial amount of development investment in many countries. Construction cost overruns have become a norm in the construction industry and are common in many building projects [1]. According to a KPMG (2020) study [2] and McKinsey report, in the past three years, only $31 \%$ of all projects came within $10 \%$ of their cost estimations, and $98 \%$ of mega projects were delayed or over budget [3]. Morris and Hough studied eight construction projects in Europe and found most of the projects were not finished on time or within the estimated budget [4]. Cost overrun is a major problem in both developing and developed countries, but the trend is more acute in developing countries, where these overruns sometimes exceed $100 \%$ of the estimated construction cost [5]. For example, in Malaysia, more than $90 \%$ of

Copyright (C2021 Ming Hu, et al.

DOI: https://doi.org/10.37256/gbce. 212021768

This is an open-access article distributed under a CC BY license

(Creative Commons Attribution 4.0 International License)

https://creativecommons.org/licenses/by/4.0/ 
governmental projects have experienced delays, resulting in a significant amount of time and cost overruns [6].

Some factors causing the cost overrun were identified. Under the estimation of the original construction cost [7], change of scopes, inflation [1], incomplete design documents and specification at tendering the stage [8], poor project planning, and a lack of good project management [9] have been identified as major causes of cost overrun. Project complexity, technological requirement, and market demand were also identified as influential factors [10]. Inaccurate cost estimations must be addressed because the cost estimation is the basis for creating a project budget and schedule [11]. Moreover, inaccurate cost estimations have been recognized as one of the main causes of construction cost overruns [12]. A lack of both estimating experience [13] and practical knowledge of the construction process by the cost estimator [14] have been identified as contributors to an inaccurate estimation. There are limited studies on development in building construction cost estimation methods research since the building construction cost estimation has been viewed as a mature field in practice. However, consistent cost overruns across building types and regions prove the need for research. Furthermore, despite the large number of computerized estimation tools [15], there have been limited improvements in state-of-the-art construction cost estimation tools in order to improve accuracy [16, 17]. Consequently, inaccurate cost estimations have become a long-standing concern in the construction industry. To find a better solution to control and mitigate cost overruns, important steps include identifying and understanding current construction cost estimation practices in terms of commonly used methods and gaps.

In addition to common risk of construction cost overrun, the second area needs more research is sustainable building cost. Sustainable building has been associated with higher initial construction costs and higher risk of cost overrun. Having a better understanding of conventional building construction cost estimation method, gaps and potential improvement strategies can be beneficial to mitigate the high risk of cost overrun in sustainable building. To this extend, this study also discusses the uniqueness in sustainable building construction cost estimation, and causal effects will be identified as well. At the end, a cost estimation method integrating risk and uncertainty consideration are proposed to produce more accurate cost estimation, particularly in sustainable building construction cost.

\section{Current construction cost estimation status}

There are three research gaps in the construction cost estimation of a building: (1) a standard definition and terminology of construction cost, (2) the estimation guidelines and method, and (3) a standard definition and estimation guidelines related to sustainable building.

First, most existing literature on construction costs does not provide a clear definition about the types of costs and sometimes does not differentiate the building costs from the resale price. Fleming [18] draws a distinction between building prices and building costs by referring to the former as the market price for building work payable by a client and the latter as the costs incurred by a contractor in carrying out work. In general, the price always reflects some consideration of profits, while the term cost normally does not include profit. But sometimes price is used to derive the cost if the profit factor is known. For example, the U.S. Census Bureau estimates the construction cost of new singlefamily houses using housing starts and/or sale data from the U.S. Census Bureau's Survey of Construction (SOC). According to the SOC, the total cost of a private new single-family home is obtained by multiplying the number of units by the average construction cost per unit. For units built by the developer (to be sold or rented), the average construction cost is the average sales price at the time of the start multiplied by the factor 0.8424 . This factor eliminates an estimate of the cost of "nonconstruction" items, such as raw land, marketing costs, closing costs, profit, and movable appliances [19]. For a home built for the owner, the total cost is the average contract value at the start of construction multiplied by the factor 1.102 to eliminate "nonconstruction" items and add the value of land development not already accounted for. Therefore, the national statistics for construction costs of residential units are derived from the sale price regardless of the type, which could lead to inaccurate information about the real construction cost. In addition, such complicated and varied calculation methods cause confusion, leading to difficulty in creating a fair comparison.

Second, there is no literature on generally accepted estimation guidelines, nor are consistent terminologies used for the construction cost estimation. The existing literature primarily focuses on estimating the format and procedures and the process for a particular application [20]. There is limited attention on establishing a consistent estimation framework. The foundation cost should be included in the estimation so that relatively consistent and accurate estimation results 
can be compared and used to provide researchers and decision-makers with a more accurate cost estimation and thus mitigate a cost overrun. Even though there is considerable literature on estimating principles proposed by researchers, common methods used in the industry have not reflected recent research findings. More precisely, there is no translation from research findings to practice regarding the construction cost estimation.

Lastly, there is no consensus or standard definition of the construction cost of a sustainable building [21, 22]. Dwaikat and Ali (2016) pointed out there were few academic studies published on the topic of sustainable building construction costs, and all of the studies were published recently, following 2010. They also concluded that there was no clear methodology describing sustainable buildings' additional construction costs compared to conventional buildings. Data availability and transparency have been identified as primary barriers to studying construction costs, particularly sustainable construction costs [23]. A lack of clear methodology describing sustainable buildings' construction costs is also identified as the leading cause for ambiguity and the large variation in costs of sustainable construction [23]. Houghton et al. (2009) defined the additional first-cost of green building as the additional construction costs associated with green design and construction elements, but he did not provide a detailed explanation. Hu (2019) proposed the following components: "Building construction costs include all costs related to constructing a sustainable building, such as those of the materials, labor, equipment, and utilities, and all of the costs required prior to the completion of a building's construction," [24] which is used as the base of the definition framework proposed in this paper.

To fill the knowledge gaps mentioned above, a scoping review was conducted to gain an understanding of the cost components, the cost estimation methods, and particular factors contributing to sustainable building costs. This study focuses on bid costs, which are also referred to as estimated project costs other than the final actual construction costs. Bid costs were used due to the difficulty in obtaining actual cost information from contractors. The bid construction cost is based on the obtained cost estimation documents.

\section{Method and scope}

The research method adopted for this study is called Literature-Based Discovery (LBD) [25], which has been widely used in biomedical science research [26], life science [27], and computer science [28]. It was proposed in 1986 by Dr. Don R. Swanson from the University of Chicago. The method derives its conclusion from various published papers and bibliographic sources. The technique used in this study was a scoping review. Different from the systematic review, which identifies evidence related to particular questions and appraises and synthesizes the results of the review, a scoping review is used to determine the scope or coverage of a body of literature and is ideal for examining emerging evidence when it is still unclear what specific questions can be posed [29]. The steps undertaken in this scoping review were derived from the framework outlined by Arksey and O’Malley [30] and later extended by Levac et al. [31]. The scoping review included the following five key phases: (1) identifying the research question; (2) identifying relevant studies; (3) selecting the studies; (4) charting the data; and (5) collating, summarizing, and reporting the results. The optional "consultation exercise" of the framework was not conducted [31].

\subsection{Research questions}

This review was guided by the following questions: What are the changes in construction cost research in the past decades? Which factors contributing to the sustainable building cost are different from those of conventional buildings? For the purpose of this study, a scoping review is defined as a research synthesis that aims to map the terminologies, estimation methods, and contributing factors used for determining the construction cost of conventional buildings and sustainable buildings. The goal is to propose a consistent framework that can be used in the next step to study the additional costs for sustainable buildings.

\subsection{Data sources and search strategy}

The initial search was implemented in June 2020 through two databases: Scopus (Construction and Building Materials, Buildings, Automation in Construction, 1997-Present) and Web of Science (Building Construction Technology, Civil Engineering, Architecture, 1900-Present). The two databases offer comprehensive platforms for 
publications in building and construction management research, and the publications indexed in these two databases tend to differ [32]. No limits on data or language were placed on the database search, but the book review and conference abstract were excluded; only peer-reviewed papers and journal papers were included. The search query consisted of the following terms: construction cost, building, sustainable building.

\subsection{Identifying relevant studies}

A two-stage screening process was used to assess the relevance of studies identified in the search. For the first level of screening, only titles and abstracts of citations were used to filter out irrelevant studies, such as construction cost studies of infrastructure projects. The eligibility criteria were as follows: the article must (a) focus on building construction cost and (b) journal paper and proceeding paper. The first screening yielded 218 publications. The second level of screening was the full-text screening. For those articles that were not available through the author's institutional account or open-access, the research team reached out to authors to procure the publications. The characteristics of each full-text article were examined by the research team; those articles that did not meet the eligibility criteria were excluded. The eligibility criteria were as follows: the article must (a) include a definition of building construction cost, (b) list the building construction cost components/categories, and (c) explain the cost estimation method employed. Publications focused on the life cycle cost were not eligible for inclusion if they did not have clearly defined components in the initial building construction cost. Other publications only focusing on the costs of certain building materials or systems were excluded as well; for example, Oh et al. concentrated on the composite columns in green buildings [33], and Khabaz [34] focused on green roofs. Lastly, studies on cost and benefit analysis that did not provide detailed information on cost components and the estimation method were excluded from the analysis, but their reference lists were reviewed to identify potentially relevant studies.

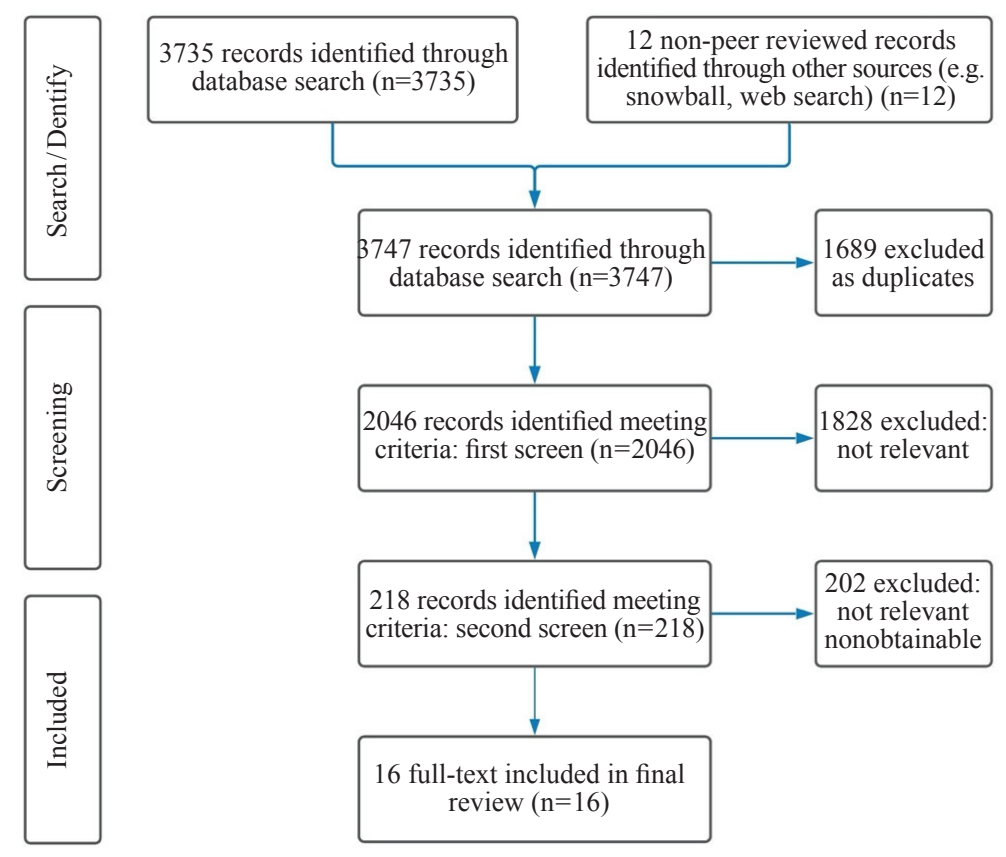

Figure 1. PRISMA flowchart of the study selection process

\subsection{Study selection}

Figure 1 illustrates the study selection process. The original search yielded 3,735 publications. After deduplication and the first relevance screening, 218 publications met the eligibility criteria based on the title and abstract, and 
corresponding full-text articles were procured for review. After data characterization of the full-text articles, 16 studies remained and were included in the full text review and analysis.

\section{Findings}

Figure 2 illustrates the research activities in the last three decades around the topic of building construction costs. Overall, the research of construction costs can be divided into three periods: (1) Before the 1980s, there were very few scientific research publications that focused on building construction costs, regardless of building construction cost estimations already being a relatively established field in practice. (2) From the early 1980s to the 1990s, there was a steady increase in publications; however, most publications were still from the trade or professional organization publishers such as Architectural Record, and the topic focused on the overall housing price fluctuations rather than cost factor analysis or cost overrun analysis. (3) From the 1990s to 2005, publications demonstrated two trends: first, an increase in alternative construction cost estimation methods other than the traditional bottom-up method and second, the start of cost estimations for green building.

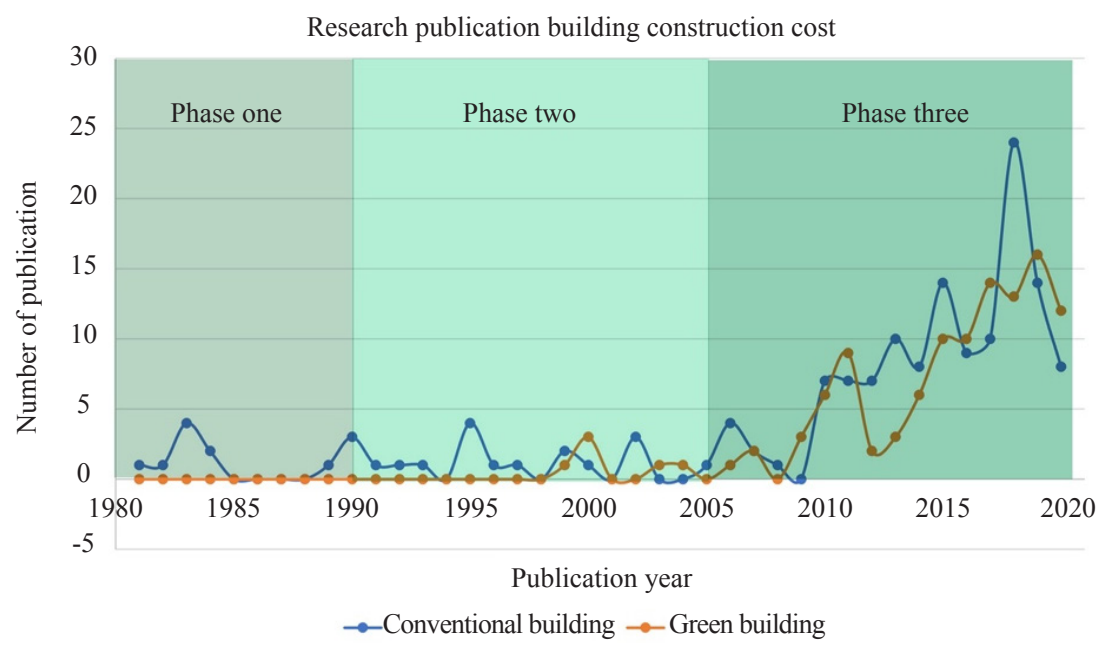

Figure 2. Publication on building construction cost and green building construction cost

In the early 1990s, sustainable or green buildings were not well defined, so publications related to green building costs were often titled as "cost of $\mathrm{CO}_{2}$ reduction". For example, one of the earliest studies published (Tiwari and Parikh) used a parametric cost model to study the construction cost increase and $\mathrm{CO}_{2}$ emissions reduction by replacing non-sustainable building materials (cement) with sustainable building materials (lime). The researchers found that a $21 \%$ emissions reduction produced a $27 \%$ increase in building construction costs that was mainly related to materials and labor costs [35]. Around 2006, there was a major jump in interest in building construction cost research, both in conventional buildings and green buildings. From 2006 to 2015, a variety of cost factors were investigated besides the material and labor costs; multiple regression was a commonly used technique [36]. Also, during this period, there was an overlapping between conventional building construction cost research and green building cost research. One of the most cited papers, "Construction cost comparison between green and conventional office buildings," was published in 2013 [37], and the majority of such comparisons are based on expert interviews or surveys [38]. After 2015, there has been increasing interest in improving research methods to gain a more quantitative understanding of how the conventional building and green building construction costs are affected. There has been an exponential increase in exploration to integrate and introduce new tools, models and methods in traditional construction cost estimations and analysis. New methods and tools include the Monte Carlo simulation [39], stochastic annuity method [40], neural network model [41] and BIM-based construction cost estimation [42]. They have been applied in both conventional and sustainable building 
construction cost estimations and analysis. A unique shift regarding the sustainable building construction cost has been increasing interest in building life cycle cost analysis, with 10 out 13 green building life cycle cost studies being published after 2015.

In the following sections, more detailed explanations are provided for cost component and method change, based on the time sequence outlined above.

\subsection{Cost categories and components definition change through the time}

For the cost unit used, a variety of terminologies are used: first cost, capital cost [43], investment cost [44], direct cost, indirect cost, hard cost, and soft cost. The most commonly used pairs of terminologies are direct cost/indirect cost and hard cost/soft cost. In this session, the items included in those cost categories are examined.

\subsubsection{Direct costs vs. indirect costs}

Carr was the first to clearly define direct costs as the costs that are traceable to physical activity [21]; therefore, it is not a direct cost if an activity has not been performed [21]. The indirect costs are business costs other than the direct cost of construction activities; they are not physically traceable and are counted even if the activity is not performed. An indirect cost is also known as overhead [21]. The Association for the Advancement of Cost Engineering International (AACE) defined direct costs as those resources that are expended solely to complete the activity or asset. The direct cost includes the cost of materials, labor, and equipment, while the indirect cost (overhead) consists of project overhead and general overhead. Project overhead includes the costs that are economically traceable to a project, such as a superintendent's salary and a tower crane rental. Small items and tools, such as nails and wires, are also considered project overhead. General overhead includes general office overhead, which is not typically traceable to construction activities or a project but is necessary for operating an office and obtaining work and other administrative work. Such overhead includes general office and warehouse rentals, insurance, salary and others (refer to Table 1).

Table 1. Direct and indirect cost breakdown (adopted from AACE manual, 6th edition)

\begin{tabular}{ccc}
\hline Categories & Items & Sub items \\
\hline Direct & Material & Contractors \\
& Labor & Design professional \\
Equipment & \\
Permit fee & \\
& Project overhead & Labor (superintendent salary) \\
& & Equipment (tower crane rental) \\
Indirect & Materials (nails, wires, etc.) \\
& General office/admin. salary \\
& Office rental/warehouse rental \\
& Tax/insurance \\
& Office supplies \\
\hline
\end{tabular}

A survey conducted among general contractors in the United States and Canada showed more than $80 \%$ of contractors estimated the direct cost and project overhead cost in a detailed manner, and only $18 \%$ of contractors estimated the general overhead cost in detail [45]. In addition, uncertainty is reflected in the contingency included in estimations, and there is a lack of decision-support tools that go beyond the mathematical calculation of the direct cost [46]. 


\subsubsection{Variable costs vs. fixed costs}

Another way to classify the construction cost is to differentiate the costs as variable costs and fixed costs [31]. This is a similar method used with accounting principles. Concrete work can be measured in square feet (meters), dry wall work can be measured in linear feet (meter), and site work can be measured in cubic yards (meters). Since the costs vary as the quantity of work changes, they can be considered variable costs. Fixed costs are those costs that must be provided and are independent of the volume of work activity. These costs remain the same, despite the change of work quantity and volume [4]. For instance, the cost to rent a tower crane per day is fixed regardless of how much work is performed. Typically, project and general overhead-such as general office rentals, administrative costs, taxes, and salaries-are fixed costs. Both variable costs and fixed costs can be direct or indirect costs. Such terms also used to describe and analysis the cost prior to more supplicated methods being introduced around 2005.

\subsubsection{Hard costs vs. soft costs}

Compared to other cost definitions, hard costs and soft costs were introduced later and are more broadly defined and less used [45] Geltner and Miller defined hard costs as a type of direct cost that can be traced back to the physical components or activities of the construction project, which include land cost, labor, materials, equipment, and the overhead cost from the contractor and developer [47] (refer to Table 2). Ade and Rehm defined the hard construction costs as those costs related to tangible and physical items required to complete the construction [46]. Soft costs were defined by Zahirah et al. as the items not directly related to the physical construction of the buildings but that are necessary for the administration of a building project [48]. Ade and Rehm described the costs as not directly contributing to construction activities but necessary to finish the construction of the project, such as administration fees, design fees, and auditing fees [46]. Because of this broader definition, they found soft costs contributed to around $26 \%$ to $33 \%$ of the total construction cost of a residential building, which is much higher than what is conventionally counted and cannot be ignored. However, in terms of what should be included in the soft cost, there is no consistent framework. Geltner et al. includes the design, legal, and financing fees in their study [49], while Zahirah et al. also includes certification, commissioning, marketing, and taxes [48]. In recent year, more research and focus has been shifted on soft costs, as the complexity of the project increase, the percentage of soft cost in total construction cost increase as well.

Table 2. Breakdown of hard vs. soft costs

\begin{tabular}{lcc}
\hline & Items & Sub items \\
\hline Land & \\
Materials & \\
Labor & \\
Equipment costs & Developer \\
& Overhead costs & Contractor \\
\hline Professional service fee & Architect/engineer \\
Certification fee & Sustainable consultant \\
Legal fee & \\
Administration fee & General office/admin. salary \\
& Commissioning & \\
\hline & Tax/insurance & \\
\hline
\end{tabular}




\subsubsection{Initial cost and life cycle cost}

The initial cost, or capital cost, sometimes has been used interchangeably with the construction cost. Fuller defined the initial cost as a capital investment that includes land acquisition, construction costs (or renovation) and the equipment costs needed to operate the building [50]. Qian and Foogn included all costs associated with procurement, supply, transport and installation in the initial cost [51]. In general, the initial cost includes the construction cost but goes beyond the costs associated with construction activities.

Life cycle cost analysis was first introduced to evaluate green building material and product studies. In 1995, the National Institute of Standards and Technology (NIST) published the Life Cycle Cost Manual (Handbook 135), which was developed for use in performing life cycle cost analysis (LCCA) of investments in federal buildings and facilities [50]. According to Handbook 135, the life cycle cost includes the initial investment, the annual cost for operation, maintenance and repairs. In later research, building demolishing and deconstruction costs were included as well [52]. Even with the early developments in the life cycle cost method and manual, the adoption of and interest in life cycle cost estimation in the building and construction industry were negligible. Even to date, the practice of LCCA in construction projects is not common. Research interest in LCCA gradually started in early 2010, mainly in green building construction costs. Understandably, the lack of interest in life cycle costs from the construction industry is caused by split incentives. The developers, contractors and design teams only bear the costs of and benefit from the initial capital investment. The life cycle cost benefit is more related to the building operators and occupants, who typically are not part of the team that makes the capital investment decisions.

\subsection{Construction cost calculation methods}

According to AACE, there are five levels of estimation that are primarily associated with project maturity: levels 1 through 5. The different levels of estimation entail different estimation methods. Generally, the estimation methods can be classified into two broad categories: conceptual and deterministic. As the level of project maturity increases, more project information is available, and the estimating method tends to progress from conceptual methods (stochastic or factored model) to deterministic methods [11]. There are two factors that differentiate conceptual methods from deterministic methods. The first major difference is that in conceptual methods the data or factors used are not a direct measure of the building being estimated, while deterministic methods use data taken from the estimated building. Related to the data difference, conceptual models require significant effort to gather the historical data prior to cost estimation; then, the gathered historical data are used to develop factors and estimating algorithms. On the contrary, deterministic methods require a large effort during the estimation to measure the quantity and volume of the data taken from the actual building.

Table 3. Estimation methods and levels (adopted from AACE)

\begin{tabular}{|c|c|c|c|c|}
\hline Estimated level & $\begin{array}{l}\text { Maturity level of project } \\
\text { (\% complete design) }\end{array}$ & Method & Expected accuracy & $\begin{array}{c}\text { End usage } \\
\text { (purpose of estimation) }\end{array}$ \\
\hline 1 & $65 \%-100 \%$ & deterministic & $-10 \%$ to $+15 \%$ & Final bid/tender \\
\hline 2 & $30 \%-75 \%$ & deterministic & $-10 \%$ to $+15 \%$ & $\mathrm{Bid} /$ tender \\
\hline 3 & $10 \%-40 \%$ & deterministic and/or conceptual & $-20 \%$ to $+30 \%$ & Budget authorization \\
\hline 4 & $1 \%-15 \%$ & conceptual & $-30 \%$ to $+50 \%$ & Feasibility study \\
\hline 5 & $0 \%-2 \%$ & conceptual & $-50 \%$ to $+100 \%$ & Concept screening \\
\hline
\end{tabular}

Conceptual methods are typically used for levels 4 and 5 and sometimes for level 3 . The purpose of providing a conceptual estimation is to determine an approximate potential project cost without a detailed design or clearly defined scope of work in a relatively short time. It is also used by owners and developers to evaluate whether the project or investment can meet the financial thresholds, enabling strategic decisions and establishing the project's preliminary funding. There is a wide range of methods and techniques used, such as the end-product unit method, project 
comparison method, physical dimensions method, and parametric method.

Regarding method evolvement through time, the methods described in 4.2.1 through 4.2.3 and in 4.2.5 are traditional cost estimation methods that have been used for many years. The quantity take-off method is the most commonly used method in the building industry. Unlike the traditionally used methods, the parametric cost method has been proposed and investigated from a research perspective but has not been broadly adopted in practice due to its requirement of data analytic skills. Each of the methods is explained as follows.

\subsubsection{End-product unit method (conceptual method)}

The end-product unit method is the most commonly used conceptual method in the building industry. The endproduct unit can be a hospital bed, hotel room, or parking space, among others. For instance, if we know a standard three-star hotel room's normal construction cost, we can use the unit cost and factor in the related amenity spaces (lobby, restaurant, parking, business center, etc.) to quickly estimate the total cost of a hotel with a certain number of hotel rooms. This estimated number does not account for the economy of scale, locality, and other influencing factors, but it does provide the developer with baseline information to compare options.

\subsubsection{Project comparison method (conceptual method)}

The project comparison method is often used in the early planning stage, when limited information is available to make an accurate estimation. Therefore, it is only practical to use similar projects as references based on historical information. For instance, a new elementary school's construction cost can be estimated based on existing schools in the same region that have similar student and teacher populations. This method is typically used in the planning stage, forming a preliminary estimation with low accuracy, around $-25 \%$ to $+40 \%$.

\subsubsection{Physical dimensions method (conceptual method)}

The most commonly used cost estimation method is using a square-foot or square-meter unit price based on the historical data. The database often used is RSMeans. Compared to the previous two methods, this one is more accurate, with accuracy estimated from $-15 \%$ to $+25 \%$. There are two advantages to this method: First, it is faster and easier to use. Second, it can quickly develop a cost estimation to separate the building from its core and shell, which is very useful for the later construction schedule and phase planning. The unit cost (square foot or meter) includes direct and indirect costs, varying according to location, project type, organization environment, and other factors influencing the variable portion of the cost.

\subsubsection{Parametric cost method (conceptual method)}

The parametric method is a method that was recently introduced to the building industry. It is very useful for early conceptual planning and estimation when there is very little information about the proposed project. The parametric model can be expressed as a mathematic equation representing the correlation between the estimated cost and independent variables, such as design parameters, technology availability, location factors, and construction factors. The parametric model typically involves performing data analysis using regression analysis to determine the key drivers for the model. Then, those key drivers (variables) can be included in the final combined cost estimation model, which provide the estimator with an easy and straightforward way to estimate the cost by inputting those variables (AACE) at the planning stages. For example, if we determine the key drivers for a school are the number of students, number of levels, and type of HVAC system used, then we can use those variables to estimate the construction cost before designing the building.

When the design drawings are $10 \%$ to $35 \%$ done, the parametric cost estimation can also be used as an intermediate-level estimation. This estimation is based on known building systems and assemblies instead of a detailed MOT. The database used in such a method is often based on historical data and organized in Unformat ${ }^{\mathrm{TM}}$. The accuracy of the parametric estimation is between $-10 \%$ and $+15 \%$. 


\subsubsection{Quantity take-off (QTO) method (deterministic method)}

One of the commonly used deterministic methods is the quantity take-off method, which relies on detailed information of building systems and components and the most available realistic unit prices. The first step is to take off the quantities of the materials that will be used based on the proposed design documentation and specifications. The materials and its unit prices are typically organized by Master Format ${ }^{\mathrm{TM}}$; then, the unit price is multiplied the quantity of the materials to estimate the total cost. The more accurate and detailed the material take-off, the more accurate the cost estimation. This is a bottom-up approach, and this method provides the most accurate estimation, which is typically between $-7.5 \%$ and $+10 \%$ of the construction costs in normal conditions [53]. However, because it is time-consuming and expensive, it is often conducted in a later stage of the project, when the majority of the project design is complete.

\subsection{Current sustainable building cost estimation practices}

To date, there is no commonly accepted sustainable building construction cost definition or comprehensive description of the components that should be included in the sustainable building construction cost [23]. The cost estimation and calculation of sustainable buildings are conducted in the same way as for conventional buildings. Sustainable materials, sustainable equipment, and sustainable systems have been identified as contributing factors to the higher cost [54]. RSMeans is the most widely used building construction cost database in the United States. It includes a section on green commercial/industrial/institutional building cost data; however, the data resources are not explained. The research team reached out to the publisher of RSMeans to inquire about the data sources and collection method, but no response has been received. This raises the question of how reliable those data are and whether it is good practice to continue using such nontransparent data for future project planning. Consequently, we can speculate whether the national average data has contributed largely to the inaccuracy of cost estimation and the perception of higher construction costs of sustainable buildings.

Most published textbooks and industry guidelines on construction cost estimation (including sustainable building) focus on the function of estimation and do not sufficiently address the real obstacles and problems of cost estimation, which are risk and uncertainty. Meanwhile, published literature that does address the risk and uncertainty has not been adopted nor implemented in current cost estimation practices. Therefore, as standard practice in the building and construction industry, cost estimation methods are the same as they were several decades ago. Akintoye pointed out that although a wealth of prescriptive literature has looked into the factors that help determine what cost estimation method to use, there is not enough information to conclude what the determining factors are [14]. There is a high degree of subjectivity involved in cost estimation, especially in indirect cost estimation [14]. Because of the high uncertainty about qualitative data and knowledge that are often vague and difficult to structure and quantify, these subjective estimations are often based on the judgement of senior management [14]. Such reliance on subjective judgement is also reflected in sustainable building cost estimations. The difference is that a large number of sustainable building systems, practices, and construction methods are relatively unfamiliar and new to experienced cost estimators and projects. Consequently, the estimations are more inaccurate compared to those of conventional buildings. Using traditional cost estimation methods to address such uncertainty and risk in sustainable buildings is not sufficient. More control for advanced uncertainty and risk is needed, which is described in Section 5.

\subsection{Causes identified for differences in sustainable building construction costs}

The literature revealed three potential causes for higher sustainable building construction costs. The first is the materials supply, which is related to the maturity of the supply chain. The scarcity of sustainable label-certified materials leads to higher costs and longer procurement times [55]. Zhang et al. found that sustainable materials can cost up to 4\% more than conventional materials [56]. In addition, in the United States, all new materials and products need to undergo testing according to varied ASTM standards and code approval, which can lead to an increase in construction costs as well. This has a particular impact on specialty materials that can only be imported from a small number of countries. For example, due to severe deforestation in China in the past decades, in 2017, the Chinese government prohibited commercial cutting of natural forests. As a result, China's reliance on imported timbers increased from 48.4\% in 2013 to $64.4 \%$ in 2018, and the United States, Russia, New Zealand, and Canada are the four largest exporters of timber [57]. 
Consequently, the cost of importing materials is reflected in the price of building materials.

The second cost contributor is the highly efficient equipment and systems, such as heat pumps and radiant flooring. For instance, a heat pump is more efficient than a conventional furnace, but it is more expensive to install. Usually, these systems are more sophisticated, and there are limited companies and workers who have such skills and experience [58]. For the same reason, advanced sustainable building components and systems also lead to increased costs. Highly efficient windows, doors, and other façade systems often cost more as well.

The third higher cost factor is the construction means and methods. Sustainable construction methods, such as prefabrication or modular construction, can reduce construction waste. Regardless of its high quality and short construction time, prefabrication housing has been found to receive less demand. The main reason is prefabricated components are associated with higher equipment and labor costs, compared to conventional on-site construction methods that currently rely on cheap labor rates [58]. In addition, the construction methods or logistics for sustainable buildings are different in two ways. First, to achieve a sustainable building performance goal, an integrated project delivery method is often employed to align all stakeholders on boards from the beginning of the project. Such a method requires frequent and intense coordination, which consequently increases costs related to labor and time. Second, some specialty sustainable systems require different construction methods. Malet et al. pointed out that in a traditional construction practice, the tower crane enters the site once every nine months [58]; in contrast, in some sustainable construction sites, a tower crane enters the site twice every eight months. Consequently, the costs related to the tower crane contribute to the green cost surcharge.

\section{Discussion: proposed framework for estimating the green building construction cost}

As mentioned above, sustainable building construction is different from conventional building in several aspects: materials, systems and assembly, construction methods, and project delivery models. To have a more accurate cost estimation and better control of real construction costs, a different cost estimation framework is needed. The proposed framework includes three parts: (1) cost input data, (2) cost estimation method or tools, and (3) cost output. The prerequisite to creating this framework is to have a consistent, comprehensive, and cohesive definition of construction cost components.

Table 4. Proposed construction cost components and definition

\begin{tabular}{lcc}
\hline H1 & \multicolumn{1}{c}{ Hard cost: costs that can be traced back to the physical components or activities } \\
H2 & Material & Contractor \\
H3 & Labor & Design professional on-site \\
H4 & Overhead cost & Developer \\
Soft cost: costs not directly related to the physical construction of the buildings but are necessary in the administration of a building project \\
\hline S1 & Professional service fee & Architect/engineer \\
& & Custainable consultant \\
S2 & Project fee & Sustainable certification fee \\
S3 & Legal fee & Building permit fee \\
S4 & Administration fee & \\
S5 & & General office/admin. salary \\
S6 & Commissioning & Office rental/warehouse rental \\
\hline
\end{tabular}




\subsection{Cost definition}

In the proposed framework, we adopted the definition described in section 3.1.2 and categorized the cost as hard costs and soft costs (Table 4). Even though direct and indirect costs are the most commonly used definitions, they have a disadvantage related to a misperception about indirect costs. Indirect costs are often described as overhead, so the project manager often tries to reduce and control overhead in order to make the project economically viable (profitable). Research found that while indirect costs contribute a small percentage to the construction cost, they can have a large impact on the overall cost. For instance, the cost of design (paid to design professionals) is less than $10 \%$ of the construction cost, but a large body of studies ranked incomplete design documents and underestimating the design budget as among the top root causes of budget overrun [59-61]. For this reason, we believe using the hard and soft cost definitions can avoid unnecessary bias.

\subsection{Cost input data: influencing factors instead of fixed RSMeans data}

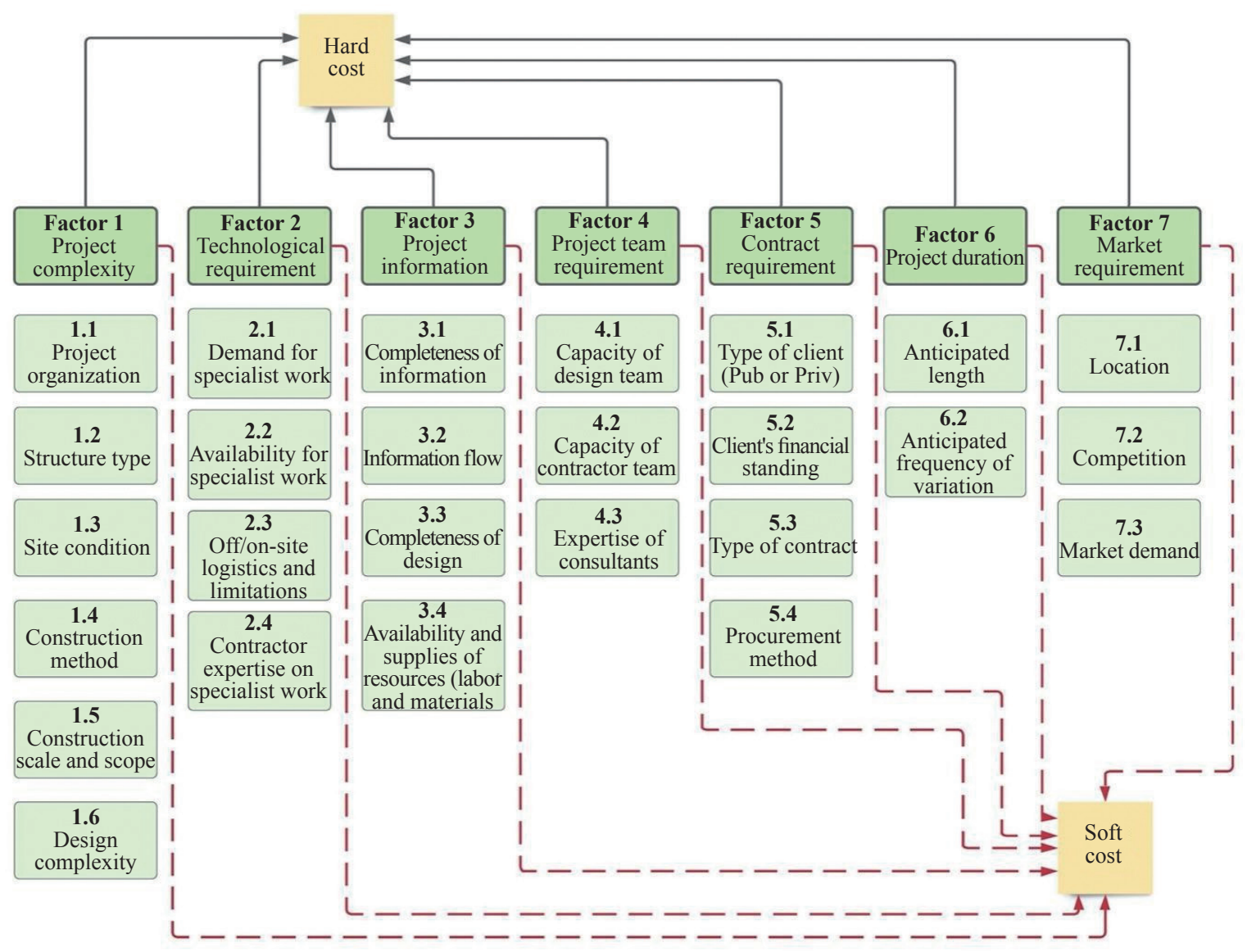

Figure 3. Influencing factors for sustainable building construction costs

The conventional estimation method relies on a cost database. As mentioned previously, RSMeans is the most widely used building construction cost database in the United States. For the most accurate deterministic estimation, building material quantities are taken off from design documents and specifications; then, the quantities are multiplied by the unit cost from the RSMeans database to compute the construction cost. Even though such an estimation method does take into consideration factors like locality and labor costs, it does not allow for the integration of uncertainty, risk, and other influential factors. As explained in the previous section, there is no agreed-upon consensus for cost factors. In this study, we adopted the seven factors identified by Akintoye that are widely cited: project complexity, technological 
requirement, project information, project team requirement, contractual arrangement, project duration, and market requirement [14]. Figure 3 illustrates the influential factors; each primary factor is composed of several sub-factors, and each of those sub-factors has different weights in terms of the deterministic effect on the primary factor. Consequentially, each primary factor has different contributing weights to the final construction cost. The weighting system is included in the parametric cost estimation model explained in Section 5.3. It is possible that different projects have different weight systems; however, we can assume a project with a similar size, type, design, and client type in a similar location can use the same weight system. The method used to acquire the weight can be categorized into subjective and objective methods. Subjective methods include entropy evaluation [60], principal component analysis [62], similarity scale based on alternative (Doga et al. 2006) [63], two-phase method [64], and genetic algorithms [65], and among others. Objective methods cover expert surveys, binomial coefficient [66], judge matrix [67], and importance ranking of attributes [68]. Some methods, such as the analytic hierarchy process, combine subjective and objective techniques.

\subsection{Cost predication model: Monte Carlo instead of traditional method}

The construction cost estimation is a prediction that provides information for decision-making. By nature, it is uncertain, and cost estimation must endure and also control uncertainty, because the uncertainty contained in an estimation is an important factor influencing a project's success as the estimated construction cost itself. The traditional cost estimation methods do not sufficiently address uncertainty, and some alternative methods have been proposed to account for the construction estimation. Akintoyei and Skitmore proposed competition-oriented methods based on competitors' prices and demand-oriented methods based mainly on the customers' perceived value [69]. Kim et al. compared the accuracy of the regression model, neural network model, and support vector machine model; they concluded the neutral network model provided a more accurate construction estimation [70]. Lee and Yu proposed a BIM and ontology-based approach for the building cost estimation [71]. Feng and Li tested a genetic algorithm in the construction cost estimate, which has higher reliability and is suitable for the practical application of engineering cost estimation [72]. Subhi and Alshamrani developed a regression model using floor height, floor area, number of floors, envelope type, and structure type to predict the initial construction cost of conventional and sustainable buildings [73]. After validation, by comparing the prediction with the real project construction cost, the accuracy from the regression model is $94.3 \%$. More advanced cost models and techniques are applied to control the uncertainty and mitigate the risk. One of the risk-based cost estimations is the Monte Carlo simulation, which is widely utilized in risk management and can be used in cost estimation. The Monte Carlo simulation is a relatively complex mathematical method of calculating the expected value as an integral using a set of random numbers against a probability density function (PDF) [74]. However, limited literature can be found on Monte Carlo simulations on sustainable building cost estimations or risk analysis [75]. We proposed a Monte Carlo simulation method based on the model often used in cost-benefit analysis.

In the proposed cost estimation method, the total construction cost will be a random variable that is the sum of a set of random numbers:

$$
C_{\text {tot }}=\sum_{i=1}^{n} C_{i},
$$

where $C_{\text {tot }}$ is the total construction cost and $C_{i}$ is the various project cost components, representing factors 1 through 6, $\left(C_{1}\right.$ though $\left.C_{6}\right) . C_{i}$ is an accumulative number, representing the sum of sub-factors (illustrated in Figure 3$)$. For the individual $C_{1}$, the cumulative cost can be calculated using the following regression formula (2):

$$
C_{i}=a+\beta_{1} C_{1 a}+\beta_{2} C_{1 b}+\beta_{3} C_{1 c}+\beta_{4} C_{1 d}+\beta_{5} C_{1 e},
$$

where $C_{i}$ is the cost of the primary factor, $C_{1 a}$ is the subfactors contributing to the cost of $C_{i}$, and $\beta_{i}$ is the weight for each sub-factor.

One of the most common sources of inaccuracy in the Monte Carlo simulation is that the cost components are assumed to be independent and to have no relation to each other, which is not the case in a construction project. For example, the capacity of the design team (factor 4.1) will impact the completeness of the design (factor 3.3), and the capacity of the contractor (factor 4.2) can determine the type of contract (factor 5.3). In general, disregarding the 
correlation between variables in a Monte Carlo simulation results in an underestimation of the total construction cost variance, which leads to cost overrun or underrun. In the proposed framework, we recommend to adopt the simplified approach and formula proposed by Touran et al. to combine highly correlated variables in order to minimize the cost variance and inaccuracy [78]. Software like Palisade @Risk is recommended to run a Monte Carlo simulation with dependent variables.

\subsection{Cost output: cost range instead of single-figure cost}

All conventional cost estimation methods, regardless of being conceptual or deterministic, are all single-point estimations. As the complexity of sustainable building increases and the lack of knowledge and training of contractors remains for some sustainable building systems, the range-cost estimation will better inform the developer and client. Chau found the more detailed the building sub-systems, the larger the number of sub-system variables there will be, leading to more unreliability in the estimator's single-figure estimate, with a higher chance of it being exceeded [76]. Methods used for range-cost estimation are the Monte Carlo simulation [77], Pareto analysis [78], and heuristics simulation, among others. Such range-cost estimations can be used as decision support tools to help a developer plan the budget and resource allocation. There has been a large body of research on using range-cost estimation in the construction industry, but it is not widely accepted by contractors yet. Instead of providing a range, contractors provide the maximum guaranteed prices based on around $80 \%$ of the project's maturity.

\section{Conclusion}

Literature on construction costs has produced a theoretical basis for general estimating principles [14], but such theories have not been widely applied in practice. Carr pointed out there is no generally accepted estimating guidelines, despite the availability of literature on forms, procedures, and principles involved in cost estimation [21]. To respond to the knowledge gap, this paper summarizes the current cost terminology, cost estimation methods, and cost influential factors for sustainable building. Furthermore, a consistent and comprehensive cost estimation method is proposed for more accurate and transparent cost estimations of sustainable buildings. Such a framework would provide a solid foundation for further development and validation of advanced cost estimation methods for construction projects. As discovered from this scoping review, in recent years, there have been several advanced estimating methods developed to address the inaccuracy of the construction cost estimation for sustainable buildings. However, those methods only exist in the literature, such as the parametric model using regression or the Bayesian model [79]. The discrete model using linear programming or classical optimization [62] was adopted in practice. The second critical shortcoming of the current sustainable building cost estimation is the ignorance of the process. Arguably, all existing cost estimation methods are based on characteristics of the finished building product rather than the process involved in constructing the building. Sustainable buildings often require an integrated project delivery method, which is different from the traditional delivery method in scheduling, staffing, and budgeting. Consequentially, the cost estimation should reflect those changes, but conventional estimating methods based on materials, labor, and equipment are not sufficient to reflect such differences. As a next step, we will further define the estimation approach and equation mentioned in section 5.3 and conduct testing with real project information and data using Palisade @Risk software to validate the effectiveness and accuracy of the proposed cost estimation framework.

\section{Reference}

[1] Subramani T, Sruthi PS, Kavitha M. Causes of cost overrun in construction. IOSR Journal of Engineering. 2014; 4(6): $1-7$.

[2] Autodesk Construction Cloud. 100+ Construction Industry Statistics. Available from: https://constructionblog. autodesk.com/construction-industry-statistics/ [Accessed 15th November 2020].

[3] McKinsey \& Company. Infrastructure productivity: How to save \$1 trillion a year. Available from: https://www. mckinsey.com/business-functions/operations/our-insights/infrastructure-productivity [Accessed 15th November 
2020].

[4] Morris PW, Hough GH. The Anatomy of Major Projects: A Study of the Reality of Project Management. New York, United States:Wiley; 1988.

[5] Reina P, Angelo WJ. Megaprojects need more study up front to avoid cost overruns. ENR. 2002; 249(3): 15.

[6] Abdullah MR, Abdul Azis AA, Abdul Rahman I. Causes of delay and its effects in large MARA construction project. International journal of Integrated Engineering (Issue on Mechanical, Materials and Manufacturing Engineering). 2009.

[7] Ali AS, Kamaruzzaman SN, Sulaiman R, Peng YC. Factors affecting housing maintenance cost in Malaysia. Journal of Facilities Management. 2010; 8(4): 285-298.

[8] Jamaludin SZ, Mohammad MF, Ahmad K. Enhancing the quality of construction environment by minimizing the cost variance. Procedia-Social and Behavioral Sciences. 2014; 153: 70-78.

[9] Chitkara KK. Construction Project Management. Tata McGraw-Hill Education; 1998.

[10] Toh TC, Ting C, Ali KN, Aliagha GU, Munir O. Critical cost factors of building construction projects in Malaysia. Procedia-Social and Behavioral Sciences. 2012; 57: 360-367.

[11] Goodman AS, Hastak M. Infrastructure Planning, Engineering, and Economics. McGraw-Hill Education; 2015.

[12] Durdyev S. Review of construction journals on causes of project cost overruns. Engineering, Construction and Architectural Management. 2020. Available from: https://doi.org/10.1108/ECAM-02-2020-0137

[13] Aibinu AA, Pasco T. The accuracy of pre-tender building cost estimates in Australia. Construction Management and Economics. 2008; 26(12): 1257-1269.

[14] Akintoye A, Fitzgerald E. A survey of current cost estimating practices in the UK. Construction Management \& Economics. 2000; 18(2): 161-172.

[15] Arditi D, Suh K. An expert system for cost estimating software selection. Cost Engineering. 1991; 33(6): 9.

[16] Doloi H. Cost overruns and failure in project management: Understanding the roles of key stakeholders in construction projects. Journal of Construction Engineering and Management. 2013; 139(3): 267-279.

[17] Liu L, Zhu K. Improving cost estimates of construction projects using phased cost factors. Journal of Construction Engineering and Management. 2007; 133(1): 91-95.

[18] Fleming RW. The Labor Arbitration Process. University of Illinois Press; 1965.

[19] United States Census Bureau. Construction Spending. Available from: https://www.census.gov/construction/c30/ methodology.html [Accessed 10th August 2020].

[20] Carr RI. Cost-estimating principles. Journal of Construction Engineering and Management. 1989; 115(4): 545551.

[21] Houghton A, Vittori G, Guenther R. Demystifying first-cost green building premiums in healthcare. HERD: Health Environments Research \& Design Journal. 2009; 2(4): 10-45.

[22] Dwaikat LN, Ali KN. Green buildings cost premium: A review of empirical evidence. Energy and Buildings. 2016; 110: 396-403.

[23] Chegut A, Eichholtz P, Kok N. The price of innovation: An analysis of the marginal cost of green buildings. Journal of Environmental Economics and Management. 2019; 98: 102248.

[24] Hu M. Does zero energy building cost more?-An empirical comparison of the construction costs for zero energy education building in United States. Sustainable Cities and Society. 2019; 45: 324-334.

[25] Bruza P, Weeber M, editors. Literature-Based Discovery. Springer Science \& Business Media; 2008.

[26] Hristovski D, Peterlin B, Mitchell JA, Humphrey SM. Using literature-based discovery to identify disease candidate genes. International Journal of Medical Informatics. 2005; 74(2-4): 289-298.

[27] Weeber M, Kors JA, Mons B. Online tools to support literature-based discovery in the life sciences. Briefings in Bioinformatics. 2005; 6(3): 277-286.

[28] Gordon M, Lindsay RK, Fan W. Literature-based discovery on the World Wide Web. ACM Transactions on Internet Technology (TOIT). 2002; 2(4): 261-275.

[29] Munn Z, Peters MD, Stern C, Tufanaru C, McArthur A, Aromataris E. Systematic review or scoping review? Guidance for authors when choosing between a systematic or scoping review approach. BMC Medical Research Methodology. 2018; 18(1): 143.

[30] Arksey H, O'Malley L. Scoping studies: towards a methodological framework. International Journal of Social Research Methodology. 2005; 8(1): 19-32.

[31] Levac D, Colquhoun H, O'Brien KK. Scoping studies: advancing the methodology. Implementation Science. 2010; 5(1): $1-9$.

[32] Wuni IY, Shen GQ, Osei-Kyei R. Scientometric review of global research trends on green buildings in construction 
journals from 1992 to 2018. Energy and Buildings. 2019; 190: 69-85.

[33] Oh BK, Park JS, Choi SW, Park HS. Design model for analysis of relationships among $\mathrm{CO}_{2}$ emissions, cost, and structural parameters in green building construction with composite columns. Energy and Buildings. 2016; 118: 301-315.

[34] Khabaz A. Construction and design requirements of green buildings' roofs in Saudi Arabia depending on thermal conductivity principle. Construction and Building Materials. 2018; 186: 1119-1131.

[35] Tiwari P, Parikh J. Cost of $\mathrm{CO}_{2}$ reduction in building construction. Energy. 1995; 20(6): 531-547.

[36] Lowe DJ, Emsley MW, Harding A. Predicting construction cost using multiple regression techniques. Journal of Construction Engineering and Management. 2006; 132(7): 750-758.

[37] Rehm M, Ade R. Construction costs comparison between 'green' and conventional office buildings. Building Research \& Information. 2013; 41(2): 198-208.

[38] Djokoto SD, Dadzie J, Ohemeng-Ababio E. Barriers to sustainable construction in the Ghanaian construction industry: consultants perspectives. Journal of Sustainable Development. 2014; 7(1): 134.

[39] Hulett DT. Monte Carlo simulation for integrated cost-schedule risk analysis: concepts, methods, and tools for risk analysis and mitigation. In Handbook of Research on Leveraging Risk and Uncertainties for Effective Project Management. USA: Hulett and Associates, LLC; 2017. p. 29-60.

[40] Fregonara E, Ferrando DG. The stochastic annuity method for supporting maintenance costs planning and durability in the construction sector: A simulation on a building component. Sustainability. 2020; 12(7): 2909.

[41] Chandanshive V, Kambekar AR. Estimation of building construction cost using artificial neural networks. Journal of Soft Computing in Civil Engineering. 2019; 3(1): 91-107.

[42] Akanbi T, Zhang J, Lee YC. Automated item matching and pricing (IMP) for wood building elements to support BIM-based wood construction cost estimation. In Computing in Civil Engineering 2019: Visualization, Information Modeling, and Simulation. Reston, VA: American Society of Civil Engineers; 2019. p. 402-409.

[43] Hershfield M, Trusty W, Larsson N, Charette R. A Business Case for Green Buildings in Canada. Ottawa, Ontario: Morrison Hershfield; 2005.

[44] Green Building Council of Australia. The dollars and sense of green building. Available from: https://www.gbca. org.au/uploads/234/1002/Dollars\%20and\%20Sense\%20of\%20Green\%20Buildings\%202006.pdf [Accessed 10th August 2020].

[45] Hegazy T, Moselhi O. Elements of cost estimation: A survey in Canada and the unit. Cost Engineering. 1995; 37(5): 27.

[46] Ade R, Rehm M. At what cost? an analysis of the green cost premium to achieve 6-homestar in New Zealand. Journal of Green Building. 2020; 15(2): 131-155.

[47] Geltner D, Miller NG, Clayton J, Eichholtz P. Commercial Real Estate Analysis and Investments. Cincinnati, OH: South-western; 2001.

[48] Zahirah N, Abidin NZ, Nuruddin AR. Soft cost elements that affect developers' decision to build green. International Journal of Civil and Environmental Engineering. 2013; 7(10): 768-772.

[49] Geltner DM, Miller NG, Clayton J, Eichholtz P. Commercial Real Estate Analysis and Investments. Cincinnati, OH: South-western; 2001. p. 642.

[50] Fuller S. Life-Cycle Cost Analysis (LCAA). An Authoritative Source of Innovative Solutions for the Built Environment. National Institute of Building Sciences. 2010. Available from: https://www.wbdg.org/resources/lifecycle-cost-analysis-lcca.

[51] Qian AY, Foong WK. A cost management approach to sustainable construction: maximizing value via cost engineering techniques. Proceedings of the SB. 2013: 235-242.

[52] Gopanagoni V, Velpula SL. An analytical approach on life cycle cost analysis of a green building. Materials Today: Proceedings. 2020; 33: 387-390.

[53] Whole Building Design Guide. UFC 3-740-05 Handbook: construction cost estimating, with change 2. Available from: https://www.wbdg.org/ffc/dod/unified-facilities-criteria-ufc/ufc-3-740-05 [Accessed 10th August 2020].

[54] Russ NM, Hamid M, Ye KM. Literature review on green cost premium elements of sustainable building construction. Architecture. 2018; 9(8). Available from: https://doi.org/10.14716/ijtech.v9i8.2762

[55] Hwang BG, Shan M, Supa'at NN. Green commercial building projects in Singapore: Critical risk factors and mitigation measures. Sustainable Cities and Society. 2017; 30: 237-247.

[56] Zhang XQ, Feng WH, Li NN. Attribute recognition model based on entropy weight and its application to evaluation of groundwater quality. Applied Mechanics and Materials. 2010; 29: 2698-2702.

[57] CISION PR Newswire. China Timber Import Report 2019. Available from https://www.prnewswire.com/news- 
releases/china-timber-import-report-2019-300780873.html [Accessed 15th November 2020].

[58] Matel E, Vahdatikhaki F, Hosseinyalamdary S, Evers T, Voordijk H. An artificial neural network approach for cost estimation of engineering services. International Journal of Construction Management. 2019; 1-4.

[59] Rosenfeld Y. Root-cause analysis of construction-cost overruns. Journal of Construction Engineering and Management. 2014; 140(1): 04013039.

[60] Engel E, Fischer R, Galetovic A. Soft budgets and renegotiations in public-private partnerships. National Bureau of Economic Research. 2009.

[61] Ahiaga-Dagbui DD, Love PE, Smith SD, Ackermann F. Toward a systemic view to cost overrun causation in infrastructure projects: A review and implications for research. Project Management Journal. 2017; 48(2): 88-98.

[62] Stilp CE, Kluender KR. Efficient coding and statistically optimal weighting of covariance among acoustic attributes in novel sounds. PLoS One. 2012; 7(1): e30845.

[63] Doğan SZ, Arditi D, Günaydın HM. Determining attribute weights in a CBR model for early cost prediction of structural systems. Journal of Construction Engineering and Management. 2006; 132(10): 1092-1098.

[64] McKenzie G, Janowicz K, Adams B. A weighted multi-attribute method for matching user-generated points of interest. Cartography and Geographic Information Science. 2014; 41(2): 125-137.

[65] Özşen S, Güneş S. Attribute weighting via genetic algorithms for attribute weighted artificial immune system (AWAIS) and its application to heart disease and liver disorders problems. Expert Systems with Applications. 2009; 36(1): 386-392.

[66] Yükçü N, Öztekin E. Strategies on the evaluation of binomial coefficients for all integers. Computational Mathematics and Mathematical Physics. 2013; 53(1): 1-7.

[67] Xu YJ, Cai ZJ. Method based on fuzzy linguistic judgement matrix and trapezoidal fuzzy induced ordered weighted geometric (TFIOWG) operator for multi-attribute decision-making problems. In 2007 International Conference on Wireless Communications, Networking and Mobile Computing. IEEE. 2007. p. 5757-5760.

[68] Xu Y, Da Q. A method for multiple attribute decision making with incomplete weight information under uncertain linguistic environment. Knowledge-Based Systems. 2008; 21(8): 837-841.

[69] Akintoye A, Skitmore M. Pricing approaches in the construction industry. Industrial Marketing Management. 1992; 21(4): 311-318.

[70] Kim GH, Shin JM, Kim S, Shin Y. Comparison of school building construction costs estimation methods using regression analysis, neural network, and support vector machine. Journal of Building Construction and Planning Research. 2013; 1(1): 1-7.

[71] Lee SK, Kim KR, Yu JH. BIM and ontology-based approach for building cost estimation. Automation in Construction. 2014; 41: 96-105.

[72] Feng GL, Li L. Application of genetic algorithm and neural network in construction cost estimate. Advanced Materials Research. 2013; 756: 3194-3198.

[73] Alshamrani OS. Construction cost prediction model for conventional and sustainable college buildings in North America. Journal of Taibah University for Science. 2017; 11(2): 315-323.

[74] Touran A, Wiser EP. Monte Carlo technique with correlated random variables. Journal of Construction Engineering and Management. 1992; 118(2): 258-272.

[75] Halil FM, Ismail H, Hasim MS, Hashim H. A conceptual study on the Monte Carlo simulation for cost forecasting in the green building project. Environment-Behaviour Proceedings Journal. 2020; 5(13): 75-81.

[76] Wing Chau K. The validity of the triangular distribution assumption in Monte Carlo simulation of construction costs: empirical evidence from Hong Kong. Construction Management and Economics. 1995; 13(1): 15-21.

[77] Rausch C, Nahangi M, Haas C, Liang W. Monte Carlo simulation for tolerance analysis in prefabrication and offsite construction. Automation in Construction. 2019; 103: 300-314.

[78] Durdyev S, Ismail S. Pareto analysis of on-site productivity constraints and improvement techniques in construction industry. Scientific Research and Essays. 2012; 7(7): 824-833.

[79] Ntuen CA, Mallik AK. Applying artificial intelligence to project cost estimating. Cost Engineering (Morgantown, West Virginia). 1987; 29(5): 8-13. 